\title{
THE WELFARE IMPLICATIONS OF COSTLY LITIGATION FOR THE LEVEL OF LIABILITY
}

\author{
A. MITCHELL POLINSKY and DANIEL L. RUBINFELD*
}

\section{INTRODUCTION}

$\mathrm{T}_{\mathrm{H}}$

HE central concern of the economic theory of liability is how to induce an injurer to take the socially appropriate level of care-the level that minimizes the sum of the cost of taking care and the losses to victims. ${ }^{\prime}$ An important result in this theory is that, assuming litigation is costless, the rule of strict liability with compensatory damages leads the injurer to choose the appropriate level of care. This follows because, under strict liability with compensatory damages, the injurer's problem-minimizing his cost of care plus his cost of liability-is identical to society's problem.

The analysis of strict liability with compensatory damages is affected in two ways when litigation costs are taken into account. First, it is no longer true (as was implicitly assumed in the preceding argument) that whenever a victim suffers harm he will sue the injurer; only victims whose losses exceed their cost of litigation will sue. This difference could lead the injurer to take less care (because he will not have to pay for all of the losses he causes) or more care (because, by reducing the harm suffered by victims, he can reduce the number who sue). Second, the social problem

* Stanford University and National Bureau of Economic Research; and University of California, Berkeley, respectively. An earlier version of this article appeared as "The Welfare Implications of Costly Litigation in the Theory of Liability" (Working Paper no. 23, Law and Economics Program, Stanford Law School, January 1986). Both authors' research was supported by separate grants from the National Science Foundation (grants SES8510638 and SES-8409858, respectively). Polinsky's research also was supported by the Hoover Institution while he was a National Fellow there in 1985-86. Helpful comments were provided by Lucian Bebchuk, Thomas Campbell, Robert Cooter, Paul Joskow, Charles Kahn, John Leubsdorf, Peter Menell, Jeffrey Perloff, Ivan P'ng, David Sappington, Steven Shavell, Marilyn Simon, and Pablo Spiller.

${ }^{1}$ See, for example, John Prather Brown, Toward an Economic Theory of Liability, 2 J. Legal Stud. 323 (1973). Issues concerning victim care, injurer and victim activity levels, and risk allocation will not be treated in this article.

[Journal of Legal Studies, vol. XVII (January 1988)]

(C) 1988 by the University of Chicago. All rights reserved. 0047-2530/88/1701/0005\$01.50 
now becomes one of minimizing the sum of the cost of care, the losses of victims, and the cost of litigation. With these changes, it may no longer be desirable to set the level of liability equal to the victim's loss.

This article analyzes the socially optimal adjustment to compensatory damages when litigation is costly. ${ }^{2}$ It will be shown that strict liability with compensatory damages generally results in the injurer choosing an inappropriate level of care and in the parties incurring excessive litigation costs. Thus, it is not socially optimal to use compensatory damages. Whether compensatory damages should be adjusted upward or downward will be seen to depend on the effect of changes in the level of liability on the injurer's incentive to take care and on the victims' incentives to sue.

The possibility that the optimal adjustment to compensatory damages is positive can be illustrated by a simple example involving one injurer and one victim. Suppose there are only two levels of care that can be chosen by the injurer- "low care" and "high care." If the injurer takes low care, the victim's loss is $\$ 700$, while if the injurer takes high care, the victim's loss is $\$ 500$. The extra cost to the injurer of taking high care is $\$ 100$. Thus, ideally, the injurer would take high care. Also, let the victim's cost of litigation be $\$ 1,000$ and, for simplicity, the injurer's cost of litigation be zero.

First consider whether the ideal outcome-high care and zero litigation costs-can be achieved under strict liability with compensatory damages. Regardless of the injurer's care, the victim will not sue because his loss is less than his cost of litigation. Consequently, the injurer will take low care, and the ideal outcome will not be attained.

Now consider strict liability with liability equal to compensatory damages plus $\$ 301$. If the injurer takes low care, the victim will sue because his loss plus the adjustment exceeds his cost of litigation $(\$ 700+\$ 301>$ $\$ 1,000$ ). But if the injurer takes high care, the victim will not sue (since $\$ 500+\$ 301<\$ 1,000)$. The injurer will choose to take high care because the extra cost of taking high care $(\$ 100)$ is less than his liability if he takes low care $(\$ 700+\$ 301)$. Since there will then not be any litigation, the ideal outcome will be achieved.

The possibility that the optimal adjustment to compensatory damages is negative can be shown by modifying the example slightly. Now assume that the injurer's extra cost of taking high care is $\$ 600$ and that the victim's cost of litigation is $\$ 300$. Then the ideal outcome is for the injurer to

\footnotetext{
${ }^{2}$ Choosing an optimal adjustment to compensatory damages obviously is equivalent to choosing an optimal level of liability. The language of "adjlisting compensatory damages" is used in order to facilitate the comparison of the results in this article to the results in the conventional theory of liability (without litigation costs), in which compensatory damages are the benchmark.
} 
take low care and, as before, for there to be no litigation costs. Under strict liability with compensatory damages, the victim will sue regardless of the injurer's care; this will lead the injurer to take low care. However, if compensatory damages are adjusted downward by $\$ 401$, the victim will not sue when the injurer takes low care (since $\$ 700-\$ 401<\$ 300$ ). Thus, the ideal outcome can be attained by an appropriate downward adjustment.

These examples illustrate two general principles. ${ }^{3}$ With respect to the injurer's choice of care, adjusting damages upward when the injurer's care would otherwise be too low with compensatory damages, or downward when care would be too high, will increase social welfare. And with respect to the cost of litigation, adjusting compensatory damages downward to reduce the victims' incentives to sue will increase social welfare. The optimal adjustment to compensatory damages takes both of these considerations into account and may be positive or negative.

The main points of the article are developed in Section II using a model in which there is a single injurer and a group of identical victims, and in Section III using a model with two groups of victims. (The Appendix shows that the results of Sections II and III hold more generally.) In Section IV the same framework is used to study the rule of negligence. Section V contains some concluding remarks. ${ }^{4}$

\footnotetext{
3 Although the principles to be discussed are not completely illustrated by the examples, the generality of the principles will become apparent.

4 To our knowledge, no previous paper has addressed the question of how the optimal level of liability is affected by the presence of litigation costs. Other articles that formally consider the welfare implications of costly litigation in the theory of liability focus on different issues. For example, Jerry R. Green, Medical Malpractice and the Propensity to Litigate, in The Economics of Medical Malpractice 193-209 (Simon Rottenberg ed. 1978), and Janusz A. Ordover, On the Consequences of Costly Litigation in the Model of Single Activity Accidents: Some New Results, $10 \mathrm{~J}$. Legal Stud. 269 (1981), have analyzed the optimal standard of care under the rule of negligence. Steven Shavell, The Social versus the Private Incentive to Bring Suit in a Costly Legal System, 11 J. Legal Stud. 333 (1982), and, subsequently, Peter Menell, A Note on Private versus Social Incentives to Sue in a Costly Legal System, 12 J. Legal Stud. 41 (1983), and Louis Kaplow, Private versus Social Costs in Bringing Suit, $15 \mathrm{~J}$. Legal Stud. 371 (1986), have considered the distinction between the private and the social incentive to sue. This discussion has been nicely synthesized by Susan Rose-Ackerman \& Mark Geistfeld, The Divergence between Social and Private Incentives to Sue: A Comment on Shavell, Menell, and Kaplow, 16 J. Legal Stud. 483 (1987). There also have been several studies that analyze the effects of litigation costs in models of liability but that do not focus on welfare issues. See, for example, Janusz A. Ordover, Costly Litigation in the Model of Single Activity Accidents, 7 J. Legal Stud. 243 (1978); Ivan P. L. P'ng, Litigation, Liability, and Incentives for Care, forthcoming in J. Pub. Econ.; and Marilyn J. Simon, Imperfect Information, Costly Litigation, and Product Quality, 12 Bell J. Econ. 171 (1981). Finally, Steven C. Salop \& Lawrence J. White, Economic Analysis of Private Antitrust Litigation, 74 Geo. L. J. 1001 (1986), have informally discussed several of the issues addressed in this article in the context of private antitrust enforcement.
} 


\section{A Model with Identical Victims}

This section analyzes the rule of strict liability in a model with a single risk-neutral injurer and a fixed number of identical risk-neutral victims. The injurer chooses a level of care that determines the losses suffered by the victims. ${ }^{5}$ The victims sue if the damage award exceeds their cost of litigation (assuming they bear their own litigation costs). The social problem is to choose the level of the damage award so as to minimize the sum of the injurer's cost of taking care, the victims' losses, and the injurer's and the victims' litigation costs. The optimal award will be divided into two components: compensatory damages and an adjustment to compensatory damages.

Let

$$
c=\text { injurer's level of care. }
$$

Units of care are defined so that one unit of care costs one dollar. Let

$$
l_{0}-\lambda c=\text { each victim's loss, given injurer's care, }
$$

where $l_{0}>0$ and $\lambda>0$ are constants. ${ }^{6}$ Obviously, $l_{0}-\lambda c \geqslant 0$. Note that $\lambda$ measures the "productivity" (more precisely, the marginal benefit) of the injurer's care; the higher $\lambda$, the more productive is care. Let

$$
\begin{aligned}
& s=\text { each victim's cost of litigation }\left(s<l_{0}\right),{ }^{7} \\
& r=\text { injurer's cost of litigation per suit. }
\end{aligned}
$$

The number of victims is normalized to be unity; accordingly, reference often will be made to a single victim. Finally, let

$$
\Delta=\text { adjustment to compensatory damages. }
$$

To help interpret later results, it will be useful to derive the first-best level of care. This level of care minimizes the sum of the cost of care and the victims' losses, $c+\left(l_{0}-\lambda c\right) .^{8}$ Thus, the first-best level of care is:

$$
c^{*}= \begin{cases}l_{0} / \lambda, & \text { if } \lambda>1, \\ 0, & \text { if } \lambda<1 .\end{cases}
$$

\footnotetext{
${ }^{5}$ In the Appendix, care is allowed to affect the probability as well as the level of the loss.

${ }^{6}$ A linear loss function is used in order to solve explicitly for the optimal adjustment to compensatory damages. A general loss function is considered in the Appendix.

7 The assumption that $s$ is less than $I_{0}$ assures that there will be suits if the injurer does not take any care. Otherwise, the problem is uninteresting.

${ }^{8}$ Note that, because the number of victims is normalized to be unity, $l_{0}-\lambda c$ represents the losses of all victims.
} 
If $\lambda>1$, the marginal benefit of care, $\lambda$, is greater than the marginal cost of care, 1 . Therefore, it is socially desirable for the injurer to take enough care to eliminate the victims' losses. If $\lambda<1$, it is not socially desirable for the injurer to take any care. ${ }^{9}$

The first-best outcome consists of achieving the first-best level of care without incurring litigation costs. The first-best outcome normally will not be attainable because (i) the victims may sue the injurer in order to obtain compensation, and (ii) the injurer will choose his level of care knowing that he may not have to pay for all of the losses he causes and that his choice of care may affect the victims' decisions to sue.

Now consider the victims' and the injurer's behavior. A victim will sue if the award of compensatory damages plus the adjustment to compensatory damages exceeds his cost of litigation: ${ }^{10}$

$$
\left(l_{0}-\lambda c\right)+\Delta>s .
$$

Equivalently, the victim will sue if $c<\hat{c}$, where

$$
\hat{c}=\left(l_{0}+\Delta-s\right) / \lambda \text {. }
$$

The injurer chooses care to minimize the sum of his cost of care, cost of liability, and cost of litigation. ${ }^{11}$ This sum is:

$$
\begin{cases}c+\left(l_{0}-\lambda c+\Delta\right)+r, & \text { if } c<\hat{c} \text { (suits occur), } \\ c, & \text { if } c \geqslant \hat{c} \text { (no suits occur). }\end{cases}
$$

First note that the injurer would never choose care in excess of $\hat{c}$, the lowest level of care that forestalls suits. If care is productive, $\lambda>1$, the injurer will choose care equal to $\hat{c}$ because the marginal benefit of carein the form of reduced liability costs-exceeds the marginal cost of care; in addition, at $\hat{c}$ the injurer does not incur litigation costs. If care is unproductive, $\lambda<1$, the marginal benefit of care is less than the marginal cost of care; thus, the injurer will take zero care unless, by taking care equal to $\hat{c}$, his savings in litigation costs are sufficiently great. ${ }^{12}$

\footnotetext{
${ }^{9}$ If $\lambda=1$, the optimal level of care is either 0 or $l_{0} / \lambda$. For simplicity, this case is ignored. (Analogous cases of equality are ignored in Section III below.)

10 The assumption that a suit will not be brought when the award just equals the cost of litigation does not affect the results of the article. (Also, it is assumed that a positive loss must be incurred before a suit can be brought.)

11 This presumes that the injurer's gain from participating in the harmful activity is sufficiently great so that he will choose to participate in the activity regardless of the sum of these costs.

12 Strictly speaking, the statements in this paragraph are correct only for certain values of the adjustment to compensatory damages, $\Delta$. For example, if $\Delta$ is sufficiently high so that
} 
Before deriving the socially optimal adjustment to compensatory damages, it will be useful to consider the outcome with compensatory damages, that is, when $\Delta=0$. Suppose first that $\lambda>1$. The injurer's choice of care will be $\hat{c}=\left(l_{0}-s\right) / \lambda$ (see (3)). This level of care forestalls suits and thereby avoids litigation costs, but it is less than the first-best level of care, $l_{0} / \lambda$ (see (1)). Now suppose that $\lambda<1$. If the injurer's cost of litigation is sufficiently high, he will again take care equal to $\hat{c}$; although this level of care forestalls suits and eliminates litigation costs, it exceeds the first-best level of care (zero care). If the injurer's cost of litigation is sufficiently low, he will choose to take zero care, which is the first-best level of care. However, suits will occur (since $c<\hat{c}$ ). Thus, regardless of the productivity of care, compensatory damages do not achieve the firstbest outcome; either an inappropriate level of care is taken or litigation costs are incurred.

The socially optimal adjustment to compensatory damages, $\Delta^{*}$, depends on the productivity of care. If $\lambda>1$, the injurer's care is $\hat{c}=\left(l_{0}+\right.$ $\Delta-s) / \lambda$, and, given this level of care, no suits occur. The first-best level of care is $l_{0} / \lambda$. Therefore, the first-best level of care can be obtained by:

$$
\Delta^{*}=s>0 .
$$

This adjustment to compensatory damages makes suing more attractive to the victims and thereby requires the injurer to take greater care in order to forestall suits. Thus, if $\lambda>1$, the first-best outcome can be achieved.

If $\lambda<1$, the first-best level of care is zero care. It is possible to obtain this level of care without incurring litigation costs by adjusting compensatory damages downward to discourage victims from suing. From (3), it follows that:

$$
\Delta^{*}=s-l_{0}<0,
$$

again resulting in the first-best outcome. ${ }^{13}$

\section{A Model with Two Types of Victims}

In the previous section, the optimal adjustment to compensatory damages always achieved the first-best outcome. With the extension of the model in this section, the optimal adjustment might not be able to accomplish this.

$\bar{c}>l_{0} / \lambda$, then the injurer would never take care greater than $l_{0} / \lambda$ since no harm is suffered at this level of care. Since the analysis will show that the optimal $\Delta$ is in a range that does not contradict the statements in the text, this complication was ignored. (An analogous issue arises in Section III below.)

13 This result is similar in spirit to Kaplow's demonstration that prohibiting suits may increase social welfare when litigation is costly. Kaplow, supra note 4. 
Now assume that there are two types of victims who suffer different losses. ${ }^{14}$ The level of care chosen by the injurer determines the loss borne by each type. It is also assumed that the cost of litigation, as well as the adjustment to compensatory damages, is the same for both types of victims. ${ }^{15}$

Except for the following changes, the notation will be identical to that used in the previous section. Let

$$
\begin{aligned}
l_{1}-\lambda c & =\text { loss of victims of type } 1 \\
l_{2}-\lambda c & =\text { loss of victims of type } 2 \\
\theta & =\text { fraction of victims of type } 1 .
\end{aligned}
$$

It will be assumed that $l_{2}>l_{1}>s$; accordingly, the first type of victim will be referred to as a "low loser" and the second type as a "high loser."

The first-best level of care minimizes

$$
c+\theta\left(l_{1}-\lambda c\right)+(1-\theta)\left(l_{2}-\lambda c\right) .
$$

Therefore, the first-best level of care is:

$$
c^{*}= \begin{cases}l_{2} / \lambda, & \text { if } \lambda>1 /(1-\theta), \\ l_{1} / \lambda, & \text { if } 1<\lambda<1 /(1-\theta), \\ 0, & \text { if } \lambda<1 .\end{cases}
$$

This expression can be explained as follows. The marginal benefit of care depends on the level of care. The first unit of care benefits both low losers and high losers and therefore has a marginal benefit of $\lambda$. However, once care is high enough to eliminate the losses of the low losers but not high enough to eliminate the losses of the high losers, the marginal benefit of care falls to $(1-\theta) \lambda$. And when care is high enough to eliminate the losses of both groups, the marginal benefit of care is zero. The marginal cost of care is always 1 . Therefore, if $\lambda>1 /(1-\theta)$, then the marginal benefit of care exceeds the marginal cost of care up to the level of care that eliminates the losses of the high losers, $l_{2} / \lambda$. If $1<\lambda<1 /(1-\theta)$, the marginal benefit of care exceeds the marginal cost of care only up to the level of care that eliminates the losses of the low losers, $l_{1} / \lambda$. And if $\lambda<1$, the marginal benefit of care is less than the marginal cost of care at all levels of care.

Low losers will sue if

\footnotetext{
14 The Appendix allows for a continuum of victim types.

15 The consequences of allowing the adjustment to vary by victim type are discussed in note 17 infra.
} 

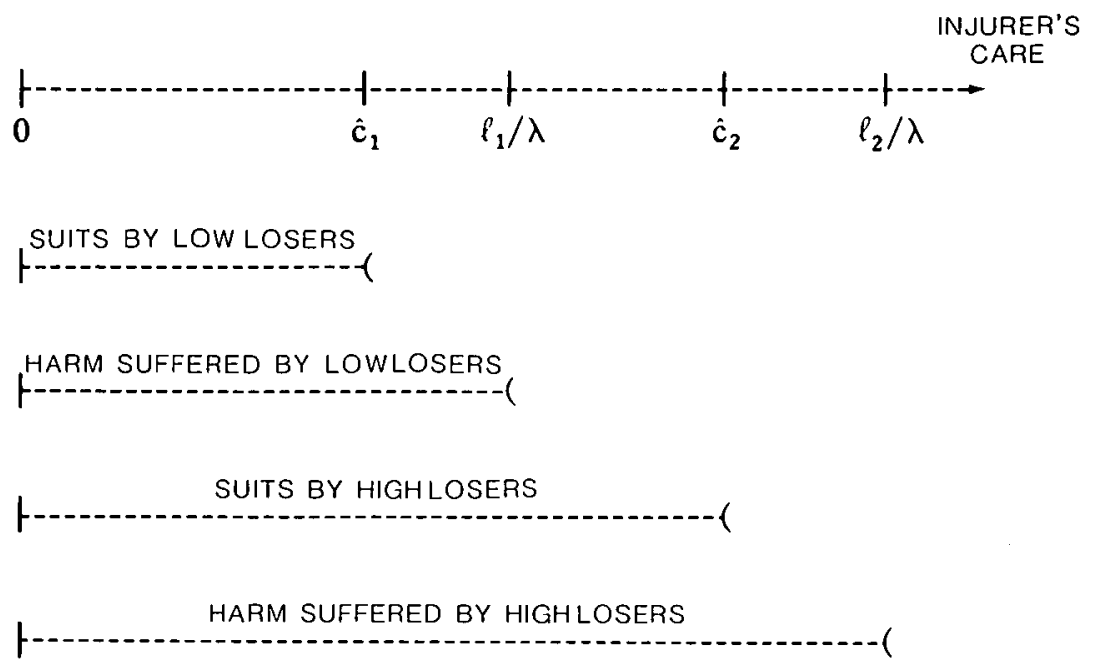

Figure 1.-Harm and suits as a function of care. This figure is based on the assumption that $s-l_{1}<\Delta<s$.

$$
\left(l_{1}-\lambda c\right)+\Delta>s
$$

or, equivalently, if $c<\hat{c}_{1}$, where

$$
\hat{c}_{1}=\left(l_{1}+\Delta-s\right) / \lambda \text {. }
$$

Similarly, high losers will sue if $c<\hat{c}_{2}$, where

$$
\hat{c}_{2}=\left(l_{2}+\Delta-s\right) / \lambda \text {. }
$$

Before proceeding, it will be useful to refer to Figure 1. This Figure shows, for each type of victim, the range of care over which harm occurs and the range over which suit occurs. Note that for some levels of care, low losers will be harmed but will not sue, while for other levels of care, high losers will be harmed but will not sue.

The injurer's choice of care and the optimal adjustment to compensatory damages will now be analyzed within each of the three relevant ranges of the productivity of care (see (8)).

\section{A. Care Very Productive $[\lambda>1 /(1-\theta)]$}

In this case, the first-best level of care is $l_{2} / \lambda$; neither low losers nor high losers would suffer harm at this level of care.

Given the high productivity of care, the injurer will continue to increase care if either group is suing. Since the lowest level of care that forestalls suits by both groups is $\hat{c}_{2}=\left(l_{2}+\Delta-s\right) / \lambda$, the injurer will take this amount of care. 
If compensatory damages $(\Delta=0)$ are used, the level of care chosen by the injurer, $\left(l_{2}-s\right) / \lambda$, will be too low. The high losers will be harmed and the low losers may be harmed, although neither group will sue. However, if the adjustment to compensatory damages is set equal to the victims' cost of litigation, $\Delta=s$, then care will increase to $l_{2} / \lambda$, the first-best level of care. Since at this level of care no one sues (because no one suffers harm), the first-best outcome is achieved.

\section{B. Care Moderately Productive $[1<\lambda<1 /(1-\theta)]$}

In this case, the first-best level of care is $l_{1} / \lambda$. At this level of care, the high losers would suffer harm but the low losers would not.

The injurer will invest in care at least up to $\hat{c}_{1}$ since, below that level, both groups would bring suit and the marginal benefit of care to the injurer would exceed the marginal cost of care. Between $\hat{c}_{1}$ and $\hat{c}_{2}$, additional care is not productive at the margin since only the high losers would be suing. However, by taking care equal to $\hat{c}_{2}$, the injurer can forestall suits by the high losers and thereby eliminate his litigation costs. Taking care above $\hat{c}_{2}$ is never worthwhile to the injurer since no one would be suing. Thus, the injurer's choice of care will be either $\hat{c}_{1}$ or $\hat{c}_{2}$.

At $\hat{c}_{1}$, the sum of the injurer's cost of care, liability, and litigation is:

$$
\begin{gathered}
\hat{c}_{1}+(1-\theta)\left(l_{2}-\lambda \hat{c}_{1}+\Delta\right)+(1-\theta) r= \\
\left(l_{1}+\Delta-s\right) / \lambda+(1-\theta)\left(l_{2}-l_{1}+s\right)+(1-\theta) r .
\end{gathered}
$$

At $\hat{c}_{2}$, the corresponding sum is:

$$
\hat{c}_{2}=\left(l_{2}+\Delta-s\right) / \lambda \text {. }
$$

Thus, the injurer will choose $\hat{c}_{2}$ over $\hat{c}_{1}$ if and only if:

$$
\left(l_{2}-l_{1}\right) / \lambda<(1-\theta)\left(l_{2}-l_{1}+s\right)+(1-\theta) r .
$$

In other words, the injurer will choose $\hat{c}_{2}$ when the extra cost of care, $\left(l_{2}-l_{1}\right) / \lambda$, is less than his savings in liability and litigation costs, $(1-\theta)$ $\left(l_{2}-l_{1}+s\right)+(1-\theta) r .^{16}$

The optimal adjustment to compensatory damages depends on whether the injurer's choice of care is $\hat{c}_{1}$ or $\hat{c}_{2}$. Suppose first that the injurer chooses $\hat{c}_{1}$. If compensatory damages are used, the injurer's care, $\left(l_{1}-s\right) / \lambda$, would be less than the first-best level, $l_{1} / \lambda$; moreover, litigation costs would be incurred because of suits by the high losers. By setting the adjustment to compensatory damages equal to the victims' cost of litigation, $\Delta=s$, the injurer can be induced to take the first-best level of care

\footnotetext{
${ }^{16}$ Note that condition (14) does not depend on $\Delta$. This is because of the linearity of the victims' loss functions.
} 
(see (10)). However, the first-best outcome cannot be achieved because litigation costs remain. ${ }^{17}$

Now suppose the injurer's choice of care is $\hat{c}_{2}$. If compensatory damages are used, the injurer's care, $\left(l_{2}-s\right) / \lambda$, could be either less than or greater than the first-best level, $l_{1} / \lambda$; however, no litigation costs will be incurred. By setting $\Delta$ equal to $s-\left(l_{2}-l_{1}\right)$, the injurer can be induced to take the first-best level of care (see (11)), again without litigation costs being incurred. Thus, the first-best outcome can be achieved. Note that the optimal adjustment, $s-\left(l_{2}-l_{1}\right)$, is positive when the injurer's care would be inadequate under compensatory damages-that is, when $\left(l_{2}-s\right) / \lambda<l_{1} / \lambda$-and negative when the injurer's care would be excessive.

\section{Care Unproductive $[\lambda<1]$}

In this case, the first-best level of care is zero. At this level of care, both low losers and high losers suffer harm.

If damages are compensatory, the injurer will take one of three levels of care: zero care, resulting in suits by both groups; $\hat{c}_{1}$, resulting in suits only by the high losers; or $\hat{c}_{2}$, resulting in no suits. Everything else equal, the higher the injurer's litigation costs, the greater the level of care he will take. Regardless of the level of care chosen by the injurer, the first-best outcome will not be achieved with compensatory damages. Either litigation costs will be incurred (if care is zero), or excessive care will be taken (if care is $\hat{c}_{2}$ ), or both (if care is $\hat{c}_{1}$ ).

However, if the adjustment to compensatory damages is sufficiently negative-equal to $s-l_{2}$-neither group will sue (see (11)). The injurer then will choose to take zero care. Hence, the first-best outcome can be achieved by an appropriate downward adjustment to compensatory damages.

\section{Summary}

The results of this section show that the optimal adjustment to compensatory damages balances two considerations-the desire to achieve the first-best level of care and the desire to avoid litigation costs. At one

\footnotetext{
17 The first-best outcome can be reached if the damage adjustment is allowed to vary across victim types. Let the adjustment for the low losers and the high losers be $\Delta_{1}=s$ and $\Delta_{2}=s-\left(l_{2}-l_{1}\right)$, respectively. It then follows from (10) and (11) that the level of care that just keeps both groups from suing is $l_{1} / \lambda$-the first-best level of care. The injurer will choose this level of care, neither group will sue, and the first-best outcome will be achieved.

Note that the optimal adjustment to compensatory damages is lower for the high losers $\left(\Delta_{2}<\Delta_{1}\right)$. This occurs because the high losers have a greater incentive to sue than the low percentage losers, everything else equal. Thus, in order to keep both groups from suing, the adjustment needs to be lower for the high losers.
} 
extreme, if care is very productive, the injurer will take enough care to forestall suits but, when damages are compensatory, not enough to prevent harm. In this case, it is desirable to adjust compensatory damages upward in order to encourage the injurer to take more care. At the other extreme, if care is unproductive, the injurer's choice of care will result in litigation costs and/or excessive care. In this case, it is desirable to adjust compensatory damages downward in order to discourage suits and/or prevent excessive care. At both extremes, the adjustment to compensatory damages leads to the first-best outcome. However, if care is moderately productive, the conflict between encouraging appropriate care and reducing litigation costs cannot always be resolved as successfully. In this case, even with the optimal adjustment to compensatory damageswhich may be positive or negative-some litigation costs may be unavoidable. ${ }^{18}$

\section{Negligence}

This section applies the framework developed in Sections II and III to the rule of negligence. It will be shown that if compensatory damages are used under the negligence rule, the injurer either will take the first-best level of care or too little care. As a result, if an adjustment to compensatory damages is needed, it must be positive.

Under a negligence rule, the injurer is liable for the victims' losses (and for any adjustment to compensatory damages) only if the injurer does not take some minimum level of care. This minimum, referred to as the standard of care, is assumed to equal the first-best level of care. ${ }^{19}$ If the standard is met, there will not be any suits (since the injurer will not be liable) and the first-best outcome will be achieved. ${ }^{20}$ Accordingly, the focus in this section is on whether compensatory damages need to be adjusted in order to get the injurer to meet the standard of care.

Since the injurer would not take more care than is required by the standard, the negligence rule never will lead the injurer to take excessive care. However, if compensatory damages are used under the negligence

18 In gereral, the possibility of settlement would lower the injurer's care. See A. Mitchell Polinsky \& Daniel L. Rubinfeld, The Deterrent Effects of Settlements and Trials (Working Paper no. 36, Law and Economics Program, Stanford Law School, October 1987). Consequently, the optimal adjustment to compensatory damages would be affected.

19 This is the usual assumption made in economic analyses of the negligence rule. See, for example, Brown, supra note 1.

20 If the analysis were extended to include uncertainty about what the standard of care is or about whether the injurer has met the standard, there would be some suits under the negligence rule. See, for example, John E. Calfee \& Richard Craswell, Some Effects of Uncertainty on Compliance with Legal Standards, 70 Va. L. Rev. 965, 974-84 (1984). 
rule, the injurer may take too little care. This is because, given the victims' cost of litigation, the level of care necessary to forestall suits may be less than the level of care required by the negligence standard. Thus, the optimal adjustment to compensatory damages under the negligence rule will always be positive (provided an adjustment is needed).

These points can be illustrated in the model with two types of victims. Consider, for example, the case in which care is moderately productive, so that the first-best level of care is $l_{1} / \lambda$. If compensatory damages are used, the level of care that forestalls suits by the low losers, $\hat{c}_{1}$, will be less than the negligence standard, $l_{1} / \lambda$, which in turn is assumed to be less than the level of care that forestalls suits by the high losers, $\hat{c}_{2}$. First note that the injurer will choose either $\hat{c}_{1}$ or $l_{1} / \lambda\left(\hat{c}_{2}\right.$ is dominated by $l_{1} / \lambda$ since the injurer would not be sued if he meets the negligence standard). If $l_{1} / \lambda$ is chosen, no adjustment to compensatory damages is necessary. But if $\hat{c}_{\mathbf{1}}$ is chosen, too little care will be taken and an upward adjustment is required. Then setting $\Delta$ equal to $s$ will lead the injurer to meet the standard and take the first-best level of care. ${ }^{21}$

Finally, observe that the optimal level of liability under negligence generally differs from that under strict liability. Section III showed that the optimal adjustment to compensatory damages under strict liability could be positive or negative, whereas this section has shown that the optimal adjustment under negligence is always positive. Also, note that the use of a negligence rule generally increases social welfare within the model because the negligence rule can achieve the same level of care as strict liability without incurring litigation costs. ${ }^{22}$

\section{Concluding Remarks}

This article has shown that strict liability with compensatory damages generally leads to a socially inappropriate level of care and to excessive litigation costs. The optimal adjustment to compensatory damages, which may be positive or negative, takes into account the effects of liability on the injurer's decision to take care, and on the victims' decisions to sue. It

21 The reasoning behind this result is essentially the same as that used to show that $\Delta=s$ leads to the first-best level of care under strict liability when the injurer chooses $\hat{c}_{1}$. See Section III.B. The only difference is that, under negligence, there is a range of adjustments that can lead the injurer to take the first-best level of care. For example, any $\Delta$ greater than $s$ will have the same effect.

22 As mentioned previously-see note 20 supra-there would be some suits (and consequently some litigation costs) under the negligence rule if uncertainty about the negligence standard or the injurer's care is taken into account. Then the comparison between strict liability and negligence is theoretically ambiguous-see, for example, Richard A. Posner, Economic Analysis of Law 528-29 (3d ed. 1986). 
was also shown that using compensatory damages under a negligence rule may lead the injurer to take too little care. A positive adjustment will then correct the problem. Although the focus in this article has been on the injurer's level of liability under strict liability and negligence, one could also use the framework developed here to study the welfare implications of costly litigation for other legal doctrines, including contributory negligence, comparative negligence, and the allocation of legal fees.

\section{APPENDIX}

This Appendix presents a more general analysis of strict liability by allowing for a continuum of victim types, a nonlinear loss function, and for the probability of harm to be dependent on the injurer's level of care. The notation will be the same as that used in the main body of the article, except for the following changes. Let

$$
\begin{aligned}
z & =\text { index of victim type }(0 \leqslant z \leqslant 1) ; \\
p(c, z) & =\text { probability of harm to victims of type } z\left(p_{1}<0, p_{2}>0\right) ; \\
l(c, z) & =\text { loss of victims of type } z\left(l_{1}<0, l_{2}>0\right) ; \\
f(z) & =\text { probability density of } z
\end{aligned}
$$

A victim will sue if $l(c, z)+\Delta>s$. Thus, the victims who sue can be identified by values of $z$ greater than $\hat{z}(c, \Delta)$, where $\hat{z}(c, \Delta)$ is defined implicitly by $l(c, \hat{z})+$ $\Delta=s$. Clearly $\hat{z}_{1}>0$ and $\hat{z}_{2}<0$.

The injurer's problem is:

$$
\underset{c}{\operatorname{Minimize}} c+\int_{\hat{z}(c, \Delta)}^{1} p(c, z)[l(c, z)+\Delta+r] f(z) d z
$$

Let $c(\Delta)$ represent the optimal level of care for the injurer, given $\Delta$. Assuming an interior optimum, it can be shown that $c^{\prime}(\Delta)>0$. Intuitively, this is because a higher $\Delta$ will induce more victims to sue, which will lead the injurer to take more care.

The court's problem is:

$$
\begin{aligned}
\underset{\Delta}{\operatorname{Minimize}} \quad c(\Delta) & +\int_{0}^{1} p(c(\Delta), z) l(c(\Delta), z) f(z) d z \\
& +\int_{\hat{z}(c(\Delta), \Delta)}^{1} p(c(\Delta), z)(r+s) f(z) d z
\end{aligned}
$$

Differentiating this expression with respect to $\Delta$ yields:

$$
\begin{aligned}
c^{\prime}(.) & +\int_{0}^{1}\left[p(.) l_{1}(.)+p_{1}(.) l(.)\right] c^{\prime}(.) f(z) d z \\
& +\int_{\hat{z}(.)}^{1} p_{1}(.) c^{\prime}(.)(r+s) f(z) d z \\
& -p(c(.), \hat{z}(.))(r+s) f(\hat{z}(.))\left[\hat{z}_{1}(.) c^{\prime}(.)+\hat{z}_{2}(.)\right] .
\end{aligned}
$$

Compensatory damages are optimal under strict liability only if the sign of this derivative is zero at $\Delta=0$. However, there is no reason to expect this to occur. 
As previously discussed, the first term is positive since a higher level of liability will cause the injurer to take more care. The second term is negative because higher care lowers the expected losses of victims. The third term is negative since higher care lowers the probability that victims suffer harm and therefore lowers expected litigation costs. And the fourth term, also involving litigation costs, can be positive or negative, depending on whether the increase in the number of suits induced by a higher level of liability is greater or smaller than the decrease in the number of suits resulting from the injurer taking more care and thereby lowering the harm suffered by victims. Thus, whether it is optimal to adjust compensatory damages upward or downward under strict liability can be seen to depend on the factors focused on in the main body of the article: how productive care is in lowering the expected losses of victims and how litigation costs are affected by the change in the level of liability. 